\title{
Development of E-learning Module for ICT Skills of Marginalized Women and Girls for ICT4D
}

\author{
https://doi.org/10.3991/ijet.v15i16.14929 \\ January D. Febro ${ }^{\bowtie}$, Mia Amor C. Catindig, Lomesindo T. Caparida \\ MSU-Iligan Institute of Technology, Iligan, Philippines \\ january.febro@g.msuitt.edu.ph
}

\begin{abstract}
The digital gender divide is a major challenge that needs to be addressed in developing countries. Thus, this work aims to address the digital illiteracy of girls and women that also fuels the digital gender divide. The goal is to produce an e-learning module that focused on the skills to be measured in assessing ICT skill in Sustainable Development Goals (SDG) 4. This can be used during trainings as a tool to capacitate participants like marginalized women and girls. The development of this e-module follows the research and development using the 4D model process: Define-Design-Develop-Disseminate. The impact of the e-learning module was evaluated during ICT literacy training for marginalized women and girls. It was found that by utilizing the e-learning module in the development of skills among participants was significant. This study was a humble step towards gaining technological skills of the marginalized girls and women in the Philippine community towards ICT4D.
\end{abstract}

Keywords-E-learning module, 4D model, ICT literacy, research and development, ICT4D.

\section{$1 \quad$ Introduction}

The ICT advancement provides opportunities for all as it acts as an indispensable function in the evolution of advanced economies and societies. It provides access to information and an avenue for economic empowerment. But as ICTs become ever more widespread, those people without access especially women and girls are prone to become increasingly deprived due to factors such as affordability, education (or lack thereof) and lack of technological literacy, as well as inherent biases and sociocultural norms that lead to gender-based digital exclusion [1]. As such, the term "digital divide" has been inevitably tied with the lack of skills, access to ICTs, inequality of access and process [2][3][4] and often exacerbates social inequalities [5].

The term "digital gender divide" has been acknowledged as a threat to establish gender equality for women [6]. It pertains to "these types of gender differences in resources and capabilities to access and effectively utilize ICTs within and between countries, regions, sectors and socio-economic groups" [7]. Accordingly, "the digital divide is composed of a skill gap and a gap of physical access to Information Technology (IT) and the two gaps often contribute to each other in circular causation. 
Without access to technology, it is difficult to develop technical skill and it is redundant to have access to technology without first having the skill to utilize it" [2]. Accordingly, "skills, skill endowment and skill demand play a fundamental role in determining, and limiting, the digital gender divide" [1]. This concept of the digital divide is often apprehended as the reason why women's power is not increasing.

ICT is considered primary to the ICT Development Index (IDI). The ICT Readiness (infrastructure access), ICT use (intensity) and ICT Capability (skills) are the three-stages needed for ICTs advancement towards reaching Information Society [8]. The focus of this study is on ICT Capability. ICTs can be a powerful tool to empower women and an enabler of economic growth, especially in under-developed areas [9][10]. One example was the ICT training conducted in the Jaipur District in India by Beena and Mathur [11], wherein 94\% who attended the training affirms that it provides technological empowerment because the acquired skills provide greater confidence and competence.

Digital literacy is "the ability to access, manage, understand, integrate, communicate, valuate and create information safely and appropriately through digital technologies for employment, decent jobs and entrepreneurship. It includes competencies that are variously referred to as computer literacy, ICT literacy, information literacy and media literacy" [12]. Sudarwati and Rukminingsih [13] argued that digital skills should be part of education for equal participation and for the benefit of everybody regardless of age and background from the vast knowledge of the web.

The progress of ICT has brought significant change to education in empowering learners. By proliferating and embedding in the education system in the Philippines elearning technology [14], the revolution of teaching and learning process had surged the academic achievements of Filipino college students [15], but not for the out of school youth and marginalized groups. Although education "is one of a nation's greatest assets and the foundation for strong and peaceful societies", it is still a major problem for developing countries. The education in the Philippines has been faced with different challenges particularly on the deficiency of its instructional materials, facilities and equipment, and even educators [16]. However, there is a continuous effort in the country not just in the incorporation of e-learning in the method of education but also to molding future e-learning developments.

In this study, the focused is on the design and development of an e-learning module given that the digital gender divide is also fueled by digital illiteracy. In this way, the benefits of ICTs can be extended more widely in society, especially to the marginalized groups. The basis of the modules' content are skills to be measured to assess ICT skill in SDG 4 and skills that could help the learners work in online jobs. The elearning module is then used during digital literacy training of marginalized women and girls. Educating the marginalized groups are very crucial as a catalyst for their empowerment. 


\section{$2 \quad$ E-Learning Content}

E-learning systems provide numerous advantages for the academe, it can minimize physical expenses of learning, enhance the learning processes management, and more importantly improve the learning [17]. Abubakar and Hassan [18] define the "Elearning concepts as the use of ICTs in the process of learning". According to Sudarwati and Rukminingsih [13], the E-learning characteristics are as follows:

1. It has contents relevant to the purposes of learning

2. It uses an instructional method, such as example, display and exercises to improve a learning process

3. It uses several elements of media such as words and pictures in order to deliver the learning materials

4. It allows a teacher-centered direct learning (synchronous e-learning) or it is designed for autonomous learning (asynchronous e-learning);

5. It constructs students' understanding and skills related to the purposes of learning, both individual and group

Hamdi and Hamtini [19] proposed a framework for developing affective e-content shown in fig. 1. The model consists of three dimensions: Learning Environment (LE), User Interface (UI) and Course Content (CC). The LE have to provide activity and assessment that will aid students to improve and evaluate their learning. It also needs to have a support interactivity to: learner-instructor interaction, learner-content interaction, and learner-interface interaction. Further, it should provide a navigation link to other software. The UI design should follow the key design principles with the aim of effective navigation of learning material. Lastly, CC should employ the cognitive theory of multimedia learning in the e-content development taking considerations on the text, image, animation, audio and video.

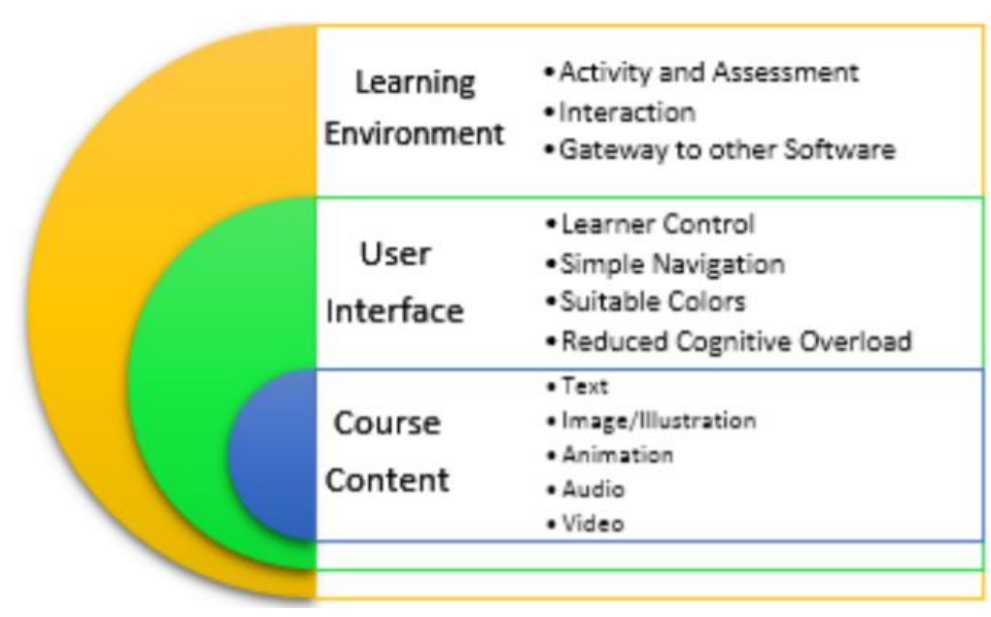

Fig. 1. H\&H Framework. Source: Hamdi \& Hamtini [19] 
Countries and the UN provided the Sustainable Development Goals blueprint as an urgent call for action to the international community. The SDG 4 and SDG 5 seeks on quality education and gender equality and women empowerment. In particular, the SDG 4 aims to ensure inclusive and equitable quality education and promote lifelong learning opportunities for all by 2030 . The target 4.4 specifically aims to substantially increase the number of youth and adults who have relevant skills, including technical and vocational skills, for employment, decent jobs and entrepreneurship. The global aim for Indicator 4.4.1 states that ICT skills are measured by the effective use of ICTs. The UN provided the skills to be measured in assessing ICT skills shown in fig. 2. These includes: connecting and installing devices, sending emails, and creating electronic presentations. Further, the SDG5 aims "to enhance the use of enabling technology, in particular ICTs, to promote women's empowerment" [20]. The global aim for Indicator 4.4.1 states that ICT skills are measured by the effective use of ICTs. This context is defined by the rapid development, complexity and the use of ICT.

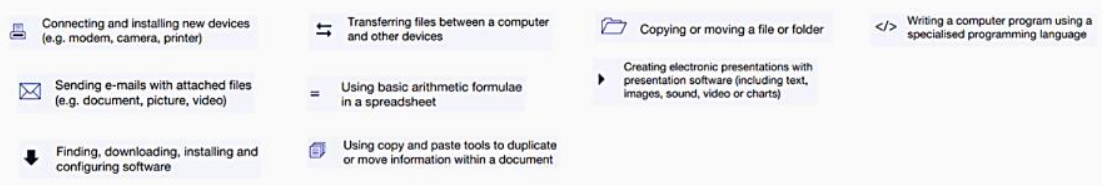

Fig. 2. Skills to be measured to assess ICT skills [14]

Moreover, the European Digital Competence Framework [21] draws competencies, DigComp. Competence areas and competencies of digital literacy global framework is shown in fig 3. In this study, the skills to be measured to assess ICT skills as defined by UIS and DigCom Competence 0 and 1 is considered in the development of the elearning module.

\begin{tabular}{|ll|}
\hline \multicolumn{1}{|c|}{ Competence area } & \multicolumn{1}{c|}{ Competences } \\
\hline $\begin{array}{l}\text { Fundamentals of } \\
\text { hardware and software }\end{array}$ & $\begin{array}{c}\text { - Basic knowledge of hardware such as turning on/off and } \\
\text { charging, locking devices } \\
\text { - Basic knowledge of software such as user account and } \\
\text { password management, login, and how to do privacy settings, } \\
\text { etc. }\end{array}$ \\
$\begin{array}{l}\text { - Browsing, searching and filtering data, information and digital } \\
\text { content } \\
\text { Information and data }\end{array}$ & $\begin{array}{l}\text {-Evaluating data, information and digital content } \\
\text { - Managing data, information and digital content }\end{array}$ \\
& $\begin{array}{l}\text { - Career-related competences refers to the knowledge and skills } \\
\text { required to operate specialized hardware/software for a } \\
\text { particular field, such as engineering design software and } \\
\text { hardware tools, or the use of learning management systems to } \\
\text { deliver fully online or blended courses. }\end{array}$ \\
\hline
\end{tabular}

Fig. 3. Competence areas and competences of the Digital Literacy Global Framework [22] 
In this study, the competencies of digital literacy global framework and ICT skills to be measured are the guide in the design and development of the e-learning material while taking consideration on the $\mathrm{H}$ and $\mathrm{H}$ framework for developing affective content.

\section{$3 \quad$ Methodology}

The suitable process for the development of the e-learning module is the 4-D model process: Define-Design-Develop-Disseminate. It is demonstrated in fig 4 as a suggested process that could be followed when developing e-learning materials. The aim was to developed e-learning module for digital literacy that can be used in training through microlearning approach. The use of microlearning is practical and it has proven by some studies to improve learner's ability in handling skill-based learning [22][23].

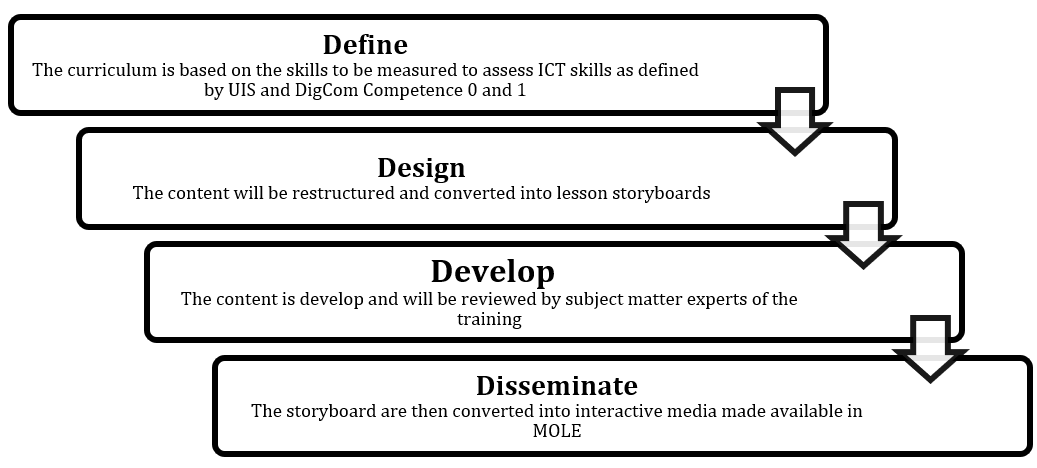

Fig. 4. Project workflow in developing an e-learning module

In define stage: needs, target audience and topic analysis are conducted. A needs analysis is carried out to establish if there is a gap in knowledge and skills of the participants of training. The design phase goal is to create instructional specification. The result of this stage is a blueprint that served as a guide in the module development. This involves drafting learning objectives and sequencing the order of objectives. For the development phase, the storyboard is first created and followed by the development of the content. This is reviewed by subject matter experts of the training. Lastly, in the disseminate stage, the courseware is disseminated and accessible through the MSU-Iligan Institute Online Learning Environment (MOLE).

\section{$4 \quad$ Results and Discussion}

The aim of this study is to develop an e-learning module for digital literacy that can be used in actual training especially to the marginalized women and girls through microlearning approach. The following subsection discusses the results of e-learning 
module development and the learning effectiveness of the training using the 4-D process.

\subsection{Define}

The define phase aimed at identifying the needs of the target audience and to conduct topic analysis prior to the development of the e-learning module. A needs analysis was carried out to establish if there was a gap in knowledge and skills. In this study, through a survey with the help of Local Government of Iligan-Gender and Development Office, it can be concluded that there is a gender digital divide of poor local communities of Iligan City, Philippines. The result of the survey also pointed out that some women and girls in the marginalized community are ICT illiterate. Hence, there is a need for ICT literacy training. Thus, the goal in this study was realized which was to design and develop the e-learning module that provides ICT literacy skills through a micro-learning approach.

Moreover, the topic content of the module was based on the "DigCom competences on fundamentals of hardware and software and information and data literacy", and skills to be measured on the global aim, indicator 4.4.1. Overall learning outcomes of the modules are depicted in fig 5:

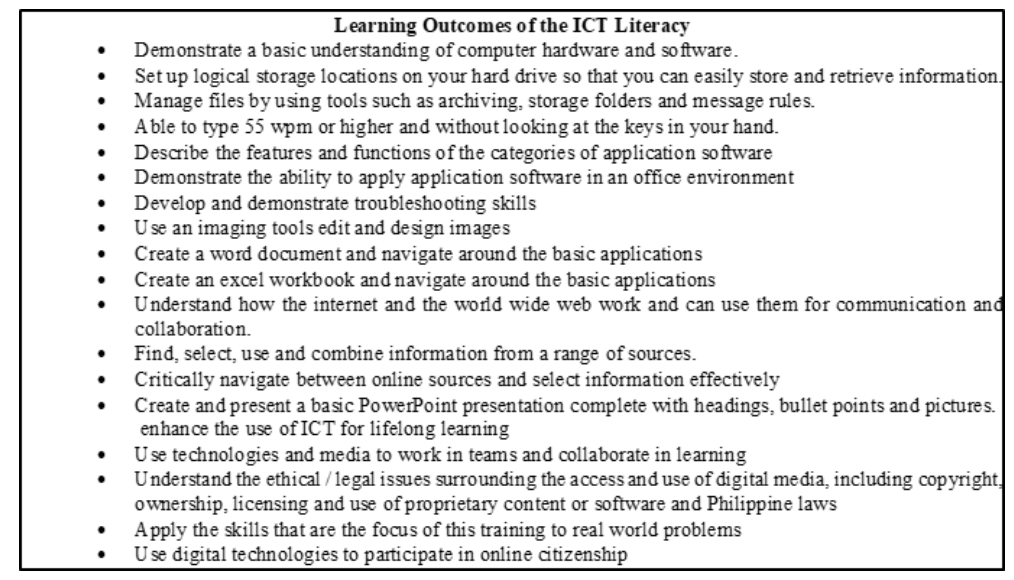

Fig. 5. Learning outcomes of the course content

\subsection{Design}

The design of the e-learning module was intended for micro-course teaching. The interactive micro-course teaching ensures students with clear learning objectives and tasks by delivering "micro-courseware, micro-video, micro-exercises, and microexamination" [24][25][26], thereby effective for ICT skills training. After the learning outcome the course content was formulated, the design phase follows- with a goal to create an instructional specification. This involves drafting learning objectives and sequencing the order of objectives. The developed module was realized with the assis- 
tance of the learning design expert. They were also responsible for the e-learning module evaluation. The content map is shown in fig 6 below. The map served as the blueprint that guides to develop the module.

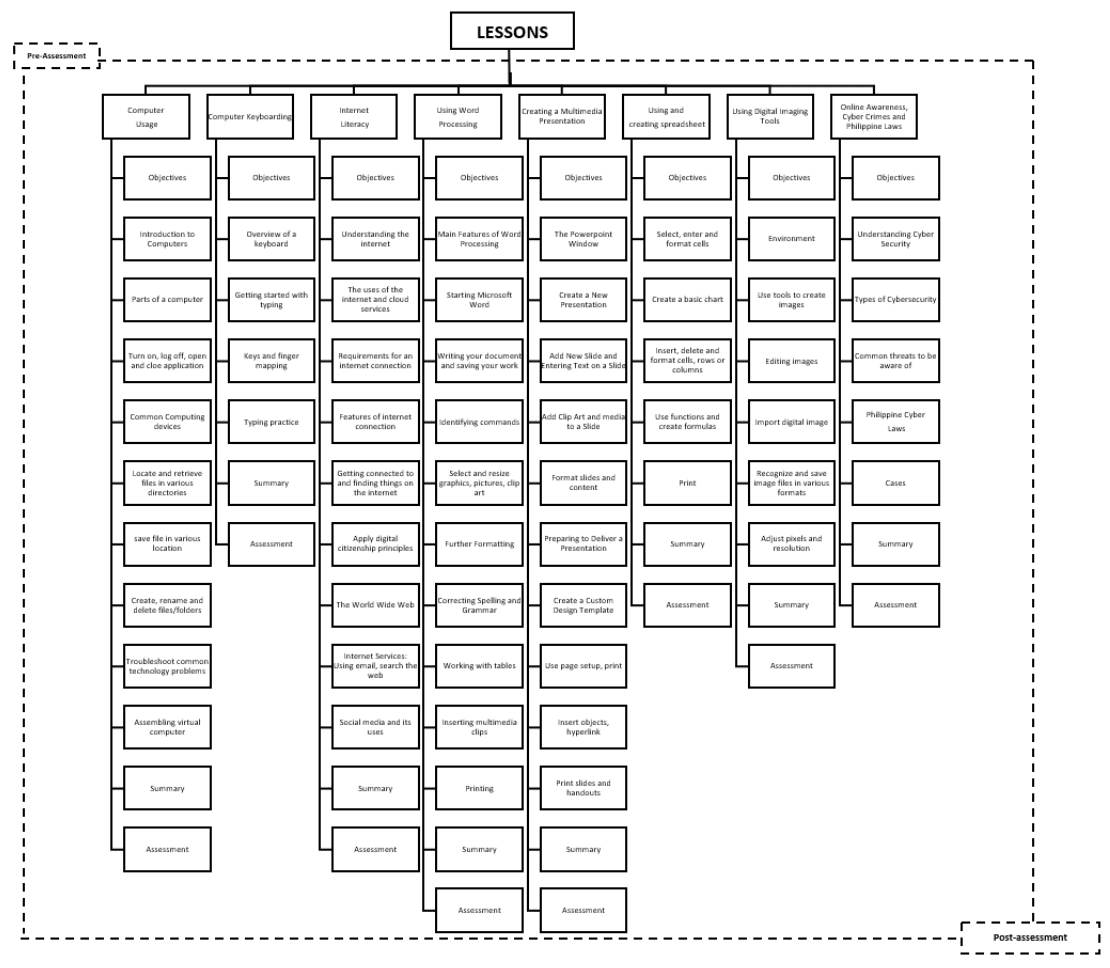

Fig. 6. Content map of the e-module

The storyboard was first created after the content was finalized. This was also reviewed by two subject matter experts of training. Instructional methods and media elements like images, text, and interactions were integrated in the storyboard. Storyboard samples are shown in fig 7 .

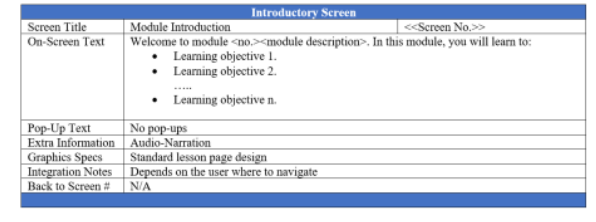

(a) e-learning module storyboard

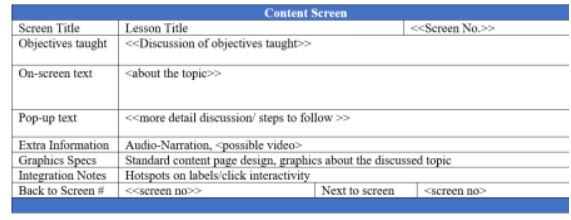

(b) introduction screen

Fig. 7. Storyboard sample 


\subsection{Develop}

In the development phase, validation of experts was very important since they gave good suggestions on what to improve, like how long should the videos be and the activities to be given. The e-learning module was then revised according to their suggestions.

The results of the validation of experts regarding the quality of the e-learning module in learning design and media design falls under good and excellent and are displayed in fig 8 below. This was done through answering a questionnaire consisted of 5 questions with a 5-point Likert scale.

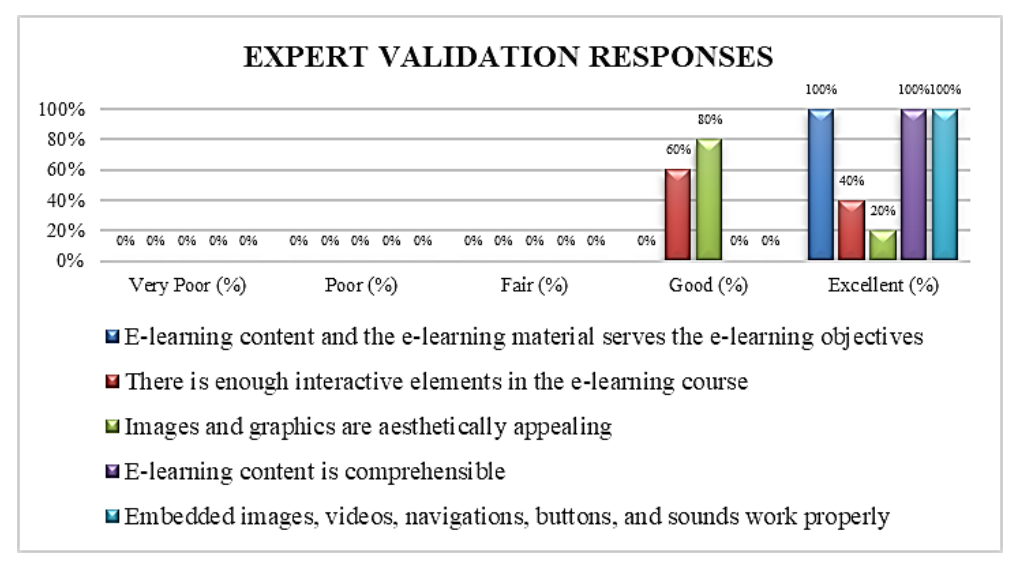

Fig. 8. Experts validation responses result

Fig 9 shows the sample interface of the final developed courseware

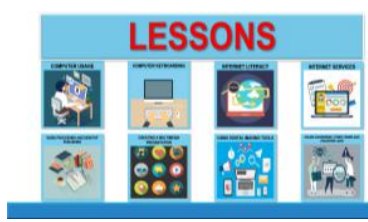

(a) Introduction screen

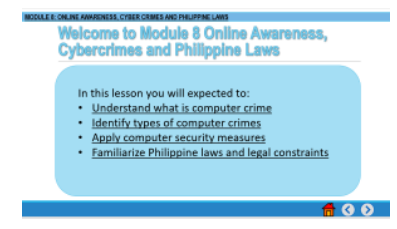

(b) e-learning module

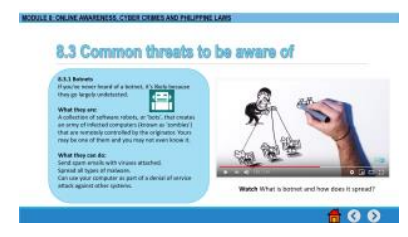

(c) content screen

Fig. 9. E-learning module content screen

\subsection{Disseminate}

The output was then ready for dissemination. As shown in fig 9, the courseware was successfully uploaded on MOLE (MSU-IIT Online Learning Environment), an online learning environment of MSU-IIT. 


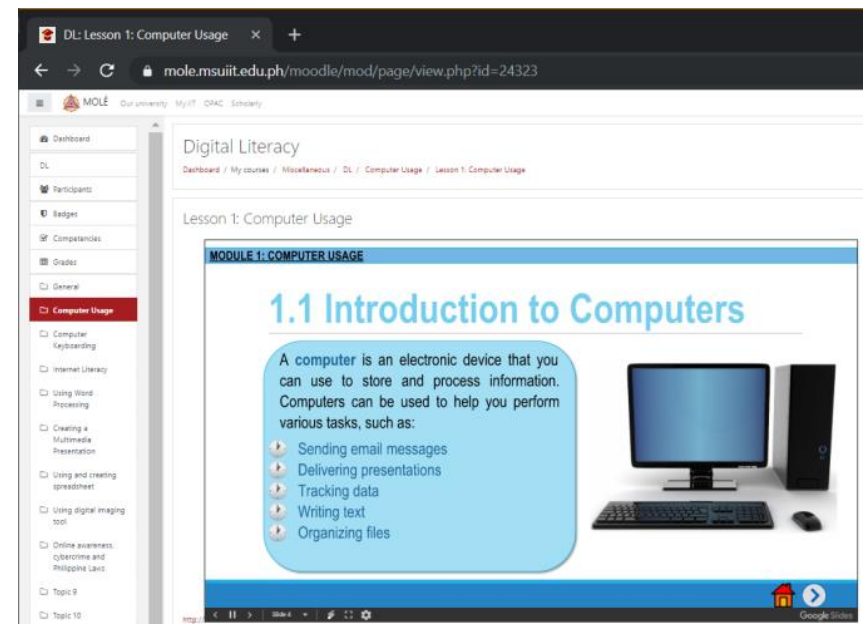

Fig. 10.Uploaded in an on-line learning environment

\subsection{Evaluation}

A pre-and-post-assessment was conducted prior to and after the training to gauge whether the participants have learned during training. The questions asked were based on the modules and the same set of questions were given for both assessments. Aside from the assessments, they were also tasked to answer the evaluation survey to get feedback from participants. The result is highly positive for the nine questions related to the participants' reaction regarding the training and the content as shown in fig 10 .

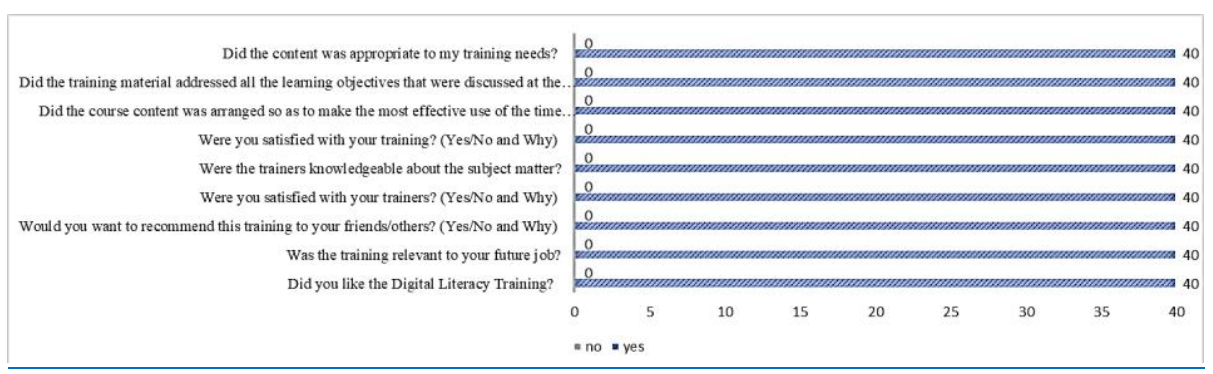

Fig. 11.Result of the post-evaluation survey

The effectiveness of the e-learning module was assessed with the learning outcomes of 40 participants in the training through an exam taken before the training started and at the end of the training. In this way, the validity of the developed module was tested. The pre-test and post-test have the same set of questions. The average score result for pre-test is 20.38 , with the highest score of 37.50 and with the lowest score of 7.5 while for the pos-test, average score is 72.63 with the highest post-test score of 97.50 and the lowest score of 50.00. The comparison of the pre-test and the post-test results is shown in fig 11 . 


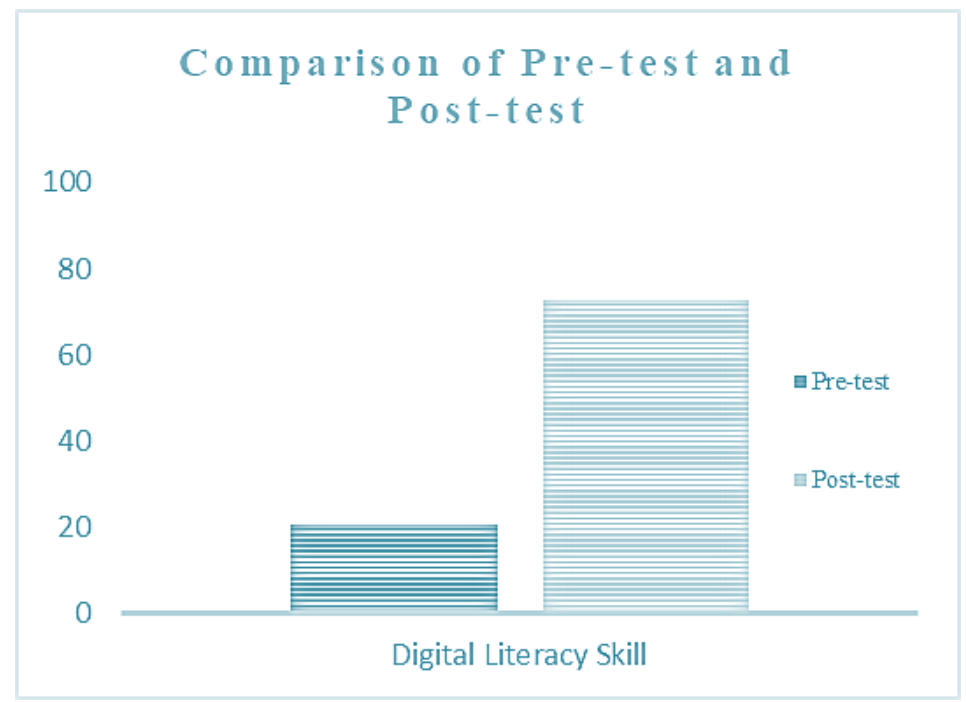

Fig. 12. Comparison of pre-test and post-test

The result is then computed to get the normalized gain average $\langle\mathrm{g}\rangle$ with the following formula [27]:

$$
<\text { g }>=\frac{\left(\%<\mathrm{S}_{\mathrm{post}}>-<\% \mathrm{~S}_{\mathrm{pre}}>\right)}{\left(100-\%<\mathrm{S}_{\mathrm{pre}}>\right)}
$$

Based on the computation of the normalized-gain test, the result is 0.6 which falls under the medium category according to Hake's interpretation of normalized gain values. This indicates a significant increase of their scores after the participants' training using the developed e-learning module. This only shows that the developed module is effective for ICT literacy training

\section{Conclusion}

The digital gender divide is still a major challenge that needs to be addressed in poor rural and urban dwellers in developing countries. Further, the education in the Philippines has been faced with different challenges, particularly on the deficiency of its instructional materials, and even educators. One solution is to utilized e-learning tools and technologies to address shortcomings. In this study, the detailed development process of the e-learning module was successfully delineated and was used as a tool to capacitate marginalized women and girls in digital literacy training. This study emphasized the value of e-learning instructional material in ICT4D. 


\section{Acknowledgement}

This work is funded by MSU-Iligan Institute of Technology.

\section{$7 \quad$ References}

[1] OECD (Organization for Economic Co-operation and Development), Bridging the Digital Gender Divide, 2018. Available: http://www.oecd.org/internet/bridging-the-digital-genderdivide.pdf https://doi.org/10.1787/852bd3b9-en

[2] C. Kularski and S. Moller, The digital divide as a continuation of traditional systems of inequality, Sociology, 5151, 1-23, 2012.

[3] J. Van Dijk and K. Hacker, The digital divide as a complex and dynamic phenomenon, Inf Soc Int J, 19, 2003. Available: https://doi.org/10.1080/01972240309487

[4] D.M. West, Digital divide: Improving Internet access in the developing world through affordable services and diverse content, Center for Technology Innovation at Brookings, 2015. Available: https://www.brookings.edu/wp-content/uploads/2016/06/West_InternetAccess.pdf

[5] A. Antonio and D. Tuffley, The Gender Digital Divide in Developing Countries. Future Internet 6(4), 2014. Available: https://doi.org/10.3390/fi6040673

[6] W20, Policy Brief - The Digital Gender Gap. Women20 Japan, 2019. Available: https://w20japan.org/pdf/digital_equity\%20_policy_biref_w20\%20Japan_final.pdf

[7] UN (United Nations), Gender equality and empowerment of women through ICT, 2005. Available: https://www.un.org/womenwatch/daw/public/w2000-09.05-ict-e.pdf

[8] ITU (The ICT Development Index (IDI), Conceptual Framework and Methodology, 2019. Retrieved: https://www.itu.int/

[9] C. Cummings and T. O'neil, do digital information and communications technologies increase the voice and influence of women and girls? 2015.

[10] Dalberg Global Development Advisors, ICT Skills for Girls and Women in Southeast Asia, The Sasakawa Peace Foundation and Dalberg Global Development Advisors, 2017. Available: https://www.dalberg.com/system/files/2017-07/ICT-Skills-for-Girls-in-Southeast-Asi a.pdf

[11] M. Beena and M. Mathur, Role of ICT Education for Women Empowerment, Int. J. Eco. Res., v3i3, $164-172,2012$.

[12] UNESCO Institute for Statistics (UIS), SDG 4 DATA DIGEST 2018: Data to Nurture Learning, 2018.

[13] N. Sudarwati and Rukminingsih, Evaluating E-Learning as a Learning Media A Case of Entrepreneurship E-Learning using Schoology as Media, iJET, Vol. 13, No. 9, 2018. Available: https://doi.org/10.3991/ijet.v13i09.7783

[14] DICT Homepage, Supply and Delivery of E-Learning Equipment and Software, 2019 Available: https://dict.gov.ph/supply-and-delivery-of-e-learning-equipment-and-software/

[15] M. Firat, Determining the Effects of LMS Learning Behaviors on Academic Achievement in a Learning Analytic Perspective, Journal of Information Technology Education: Research, pp. 75-87, 2016. https://doi.org/10.28945/3405

[16] M.B. Garcia, E-Learning Technology Adoption in the Philippines: An Investigation of Factors Affecting Filipino College Students' Acceptance of Learning Management Systems, The International Journal of E-learning and Education Technologies in the digital Media, 2017. https://doi.org/10.17781/p002374 
[17] G. Shakah, A. Al-Oqaily, and F. Alqudah. Motivation Path between the Difficulties and Attitudes of Using the E-Learning Systems in the Jordanian Universities: Aajloun University as a Case Study, iJET, Vol. 14, No. 19, 2019. Available: https://doi.org/10.3991/ijet.v $\underline{14 i 19.10551}$

[18] B.M. Abubakar and B.B. Hassan, Strategies for developing an e-learning curriculum for library and information science (LIS) schools in the Muslim world: meeting the expectations in the digital age. International Journal of Humanities and Social Science, 3(1), 163171, 2013.

[19] M. Hamdi and T. Hamtini, Designing an Effective e-Content Development Framework for the Enhancement of Learning Programming, iJET, Volume 11, Issue 4, 2016. Available: http://dx.doi.org/10.3991/ijet.v11i04.5574

[20] United Nations, The Sustainable Development Goals Report 2019. Available: https://unstats.un.org/sdgs/report/2019/The-Sustainable-Development-Goals-Report-2019. pdf

[21] European Commission, DigComp into Action - Get Inspired, Make It Happen, 2018.

[22] G. Mohammed, K. Wakil, and S. Nawroly, The Effectiveness of Microlearning to Improve Students' Learning Ability, International Journal of Educational Research Review (IJERE), 2018. https://doi.org/10.24331/ijere.415824

[23] J. Skalka and M. Drlik, Educational Model for Improving Programming Skills Based on Conceptual Microlearning Framework, $21^{\text {st }}$ International Conference on Interactive Collaborative Learning, 2018. https://doi.org/10.1007/978-3-319-75175-7 22

[24] N. Gao, Construction and Implementation of Teaching Mode for Digital Mapping based on Interactive Micro-course Technology, iJET, Vol. 13, No. 2, 2018. Available: https://doi. org/10.3991/ijet.v13i02.8317

[25] G. Sirwan, K. Wakil, and S. Nawroly, The Effectiveness of Microlearning to Improve Students' Learning Ability, International Journal of Education Research Review, 2018. https ://doi.org/10.24331/ijere.415824

[26] L. Giurgiu, Microlearning an Evolving Trend, Scientific Bulletin Vol. 22, 2017.

[27] R. Hake, Analyzing Change/Gain Scores, Dept. of Physics, Indiana University, 1997.

\section{Authors}

January Febro is an Assistant Professor of the Department of Information Technology, College of Computer Studies at Mindanao State University - Iligan Institute of Technology. J. Febro current interests involve applications for sustainable development and ICT4D.

Mia Amor Catindig is an Assistant Professor of the Department of Information Technology, College of Computer Studies at Mindanao State University - Iligan Institute of Technology. Her interests are in Data Mining, GIS Applications and Software Development.

Lomesindo Caparida is a Professor of the Department of Information Technology, College of Computer Studies at Mindanao State University - Iligan Institute of Technology. Dr. Caparida current interests involve in computer networks.

Article submitted 2020-04-13. Resubmitted 2020-05-24. Final acceptance 2020-05-26. Final version published as submitted by the authors. 